\title{
Immunogenic calreticulin exposure occurs through a phylogenetically conserved stress pathway involving the chemokine CXCL8
}

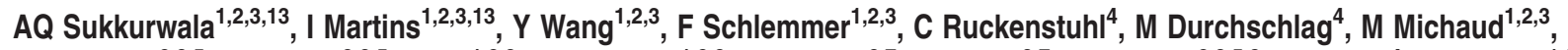

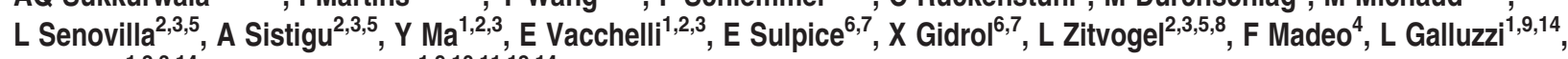 \\ $\mathrm{O} \mathrm{Kepp}^{\star, 1,2,3,14}$ and G Kroemer ${ }^{*, 1,9,10,11,12,14}$
}

The exposure of calreticulin (CRT) on the surface of stressed and dying cancer cells facilitates their uptake by dendritic cells and the subsequent presentation of tumor-associated antigens to $\mathrm{T}$ lymphocytes, hence stimulating an anticancer immune response. The chemotherapeutic agent mitoxantrone (MTX) can stimulate the peripheral relocation of CRT in both human and yeast cells, suggesting that the CRT exposure pathway is phylogenetically conserved. Here, we show that pheromones can act as physiological inducers of CRT exposure in yeast cells, thereby facilitating the formation of mating conjugates, and that a largespectrum inhibitor of G protein-coupled receptors (which resemble the yeast pheromone receptor) prevents CRT exposure in human cancer cells exposed to MTX. An RNA interference screen as well as transcriptome analyses revealed that chemokines, in particular human CXCL8 (best known as interleukin-8) and its mouse ortholog Cxcl2, are involved in the immunogenic translocation of CRT to the outer leaflet of the plasma membrane. MTX stimulated the production of CXCL8 by human cancer cells in vitro and that of Cxc12 by murine tumors in vivo. The knockdown of CXCL8/Cxcl2 receptors (CXCR1/Cxcr1 and Cxcr2) reduced MTX-induced CRT exposure in both human and murine cancer cells, as well as the capacity of the latter-on exposure to MTX-to elicit an anticancer immune response in vivo. Conversely, the addition of exogenous Cxcl2 increased the immunogenicity of dying cells in a CRT-dependent manner. Altogether, these results identify autocrine and paracrine chemokine signaling circuitries that modulate CRT exposure and the immunogenicity of cell death.

Cell Death and Differentiation (2014) 21, 59-68; doi:10.1038/cdd.2013.73; published online 21 June 2013

Chemotherapy is thought to mediate antineoplastic effects either by directly inhibiting the proliferation or by triggering the (most often apoptotic) death of cancer cells. ${ }^{1}$ Nonetheless, at least some anticancer agents display an optimal efficacy in the presence of an intact immune system, but not when mice lack T cells, dendritic cells (DCs), several other effectors of innate and adaptive immunity or when they are treated with a CD11b-specific antibody that blocks the extravasation of DC precursors. $^{2-6}$ These results point to a hitherto poorly understood role for anticancer immune responses in determining the long-term success of chemotherapy, a notion that is in line with abundant clinical data indicating that tumor infiltration by cytotoxic T lymphocytes influences disease outcome. ${ }^{7-10}$
Cancer cells respond to some chemotherapeutics such as anthracyclines and oxaliplatin by undergoing an immunogenic form of cell death, meaning that such dying cells become able to induce a potent cellular immune response on subcutaneous injection into immunocompetent mice. ${ }^{1,5,11}$ However, cell death as induced by many other agents including mitomycin $\mathrm{C}$ and cisplatin is unable to elicit such an anticancer immune response in vivo, ${ }^{12-14}$ pointing to major differences in the capacity of distinct agents to promote immunogenic cell death (ICD).

One of such differences stems from the fact that only ICD inducers are capable of triggering the pre-apoptotic exposure of calreticulin (CRT) on the outer leaflet of the

\footnotetext{
${ }^{1}$ INSERM, U848, Villejuif, France; ${ }^{2}$ Institut Gustave Roussy, Villejuif, France; ${ }^{3}$ Université Paris Sud/Paris XI, Le Kremlin Bicêtre, France; ${ }^{4}$ Institute of Molecular Biosciences, University of Graz, Graz, Austria; ${ }^{5}$ INSERM, U1015 Labellisée par la Ligue Nationale Contre le Cancer, Villejuif, France; ${ }^{6}$ Laboratoire Biologie à Grande Echelle, CEA, Grenoble, France; ${ }^{7}$ INSERM, U1038, Université Joseph Fourier, Grenoble, France; ${ }^{8}$ Centre d'Investigation Clinique Biothérapie CICBT507, Institut Gustave Roussy, Villejuif, France; ' Université Paris Descartes/Paris V, Sorbonne Paris Cité, Paris, France; ${ }^{10}$ Metabolomics Platform, Institut Gustave Roussy, Villejuif, France; ${ }^{11}$ Equipe 11 Labellisée par la Ligue Nationale Contre le Cancer, Centre de Recherche des Cordeliers, Paris, France and ${ }^{12}$ Pôle de Biologie, Hôpital Européen Georges Pompidou, AP-HP, Paris, France

${ }^{*}$ Corresponding author: G Kroemer or O Kepp, INSERM U848, Institut Gustave Roussy, Pavillon de Recherche 1, 39 rue Camille Desmoulins, F-94805, Villejuif, France. Tel: +33 14211 6046; Fax: +33 14211 6047; E-mail: kroemer@orange.fr or oliver.kepp@igr.fr

${ }^{13}$ These authors contributed equally to this work.

${ }^{14}$ These authors share senior co-authorship.

Keywords: $\alpha$ factor; autophagy; apoptosis; BAX; endoplasmic reticulum stress; PERK

Abbreviations: BCG, bacillus Calmette-Guérin; CFU, colony-forming unit; CRT, calreticulin; DC, dendritic cell; elF2 $\alpha$, eukaryotic initiation factor $2 \alpha$; ELISA, enzymelinked immunosorbent assay; ER, endoplasmic reticulum; FITC, fluorescein isothiocianate; GFP, green fluorescent protein; GPCR, G protein-coupled receptor; ICD, immunogenic cell death; IL-8, interleukin-8; mTOR, mammalian target of rapamycin; MTX, mitoxantrone; PDIA3, protein disulfide isomerase family A, member 3; PI, propidium iodide; PERK, PKR-like ER kinase; PI3K, phosphoinositide-3-kinase; r, recombinant; PTX, pertussis toxin; RFP, red fluorescent protein; SC, synthetic complete; siRNA, small-interfering RNA; SNARE, SNAP receptor; WT, wild-type; YEPD, yeast extract peptone dextrose

Received 29.1.13; revised 17.5.13; accepted 28.5.13; Edited by M Piacentini; published online 21.6.13
} 
plasma membrane. ${ }^{14}$ Cell surface-exposed CRT operates as a potent 'eat-me' signal, facilitating the engulfment of dying cells and apoptotic debris by macrophages and DCs. ${ }^{14,15}$ CRT is the most abundant soluble protein of the endoplasmic reticulum (ER) and translocates to the cell surface only in the context of an ER stress response involving the phosphorylation of eukaryotic initiation factor $2 \alpha$ (elF2 $\alpha$ ) by elF $2 \alpha$ kinase 3 (EIF2AK3, best known as PKR-like ER kinase, PERK). ${ }^{16}$ In line with this notion, lethal stimuli that fail to elicit sufficient degrees of ER stress (such as mitomycin C and cisplatin) cannot induce the immunogenic exposure of CRT on the cell surface, unless an exogenous source of ER stress is provided. ${ }^{13,17,18}$ In contrast, anthracyclines and oxaliplatin are highly efficient at stimulating the PERK-mediated phosphorylation of elF2 $\alpha$, followed by the caspase-8-mediated cleavage of BCAP31, BAX/BAK activation (presumably at the ER membrane), the anterograde transport of CRT-containing vesicles from the ER to the cell surface (via the Golgi apparatus), and - eventually - the SNAP receptor (SNARE)dependent fusion of such vesicles with the plasma membrane. ${ }^{5,16}$ In response to some (but not all) ICD inducers, protein disulfide isomerase family $A$, member 3 (PDIA3), an ER reticulum chaperone best known as ERp57, is required for the translocation of (and de facto physically escorts) CRT to the outer leaflet of the plasma membrane. ${ }^{5,16,17}$ The current literature suggests that the molecular mechanisms accounting for CRT exposure are highly complex and require further in-depth analysis. ${ }^{17,19,20}$

Extrareticular CRT is not only of immunological relevance. Indeed, CRT has been detected at the surface of capacitated spermatocytes and oocytes, ${ }^{21,22}$ and circumstantial evidence indicates that CRT contributes to the fusion of gametes and fertility, both in mammals and in nematodes. ${ }^{23,24}$ Interestingly, anthracyclines can stimulate the relocalization of Cne1p, the yeast ortholog of CRT, to the periphery of Saccharomyces cerevisiae cells, and genetic studies indicate that the mechanisms that regulate this process in mammals and yeast may be similar. ${ }^{25}$ Several unicellular parasites have also been reported to expose CRT on their surface, ${ }^{26,27}$ pointing to a broad phylogenetic conservation of the CRT exposure pathway.

Driven by these premises and incognita, we decided to reinvestigate the molecular mechanisms that underpin the immunogenic relocalization of CRT from the ER to the cell surface. Based on the initial observation that yeast pheromones induce CRT exposure to increase the formation of mating conjugates, we discovered that soluble factors regulate the translocation of CRT to the outer leaflet of the plasma membrane in mammalian cells as well. Here, we demonstrate that the chemokine CXCL8, best known as interleukin-8 (IL-8), regulates CRT exposure by binding to its cognate receptors $\mathrm{CXCR} 1$ and $\mathrm{CXRC2}$, a finding that has broad implications for the therapeutic induction of ICD in cancer patients. ${ }^{28}$

\section{Results}

Involvement of CRT exposure in yeast mating and pheromone signaling. As discussed above, CRT is physiologically exposed on the surface of gametes and favors fertilization in mammals. ${ }^{21,22,24}$ Along similar lines, $S$. cerevisiae cells lacking the yeast ortholog of CRT (Cne1p), but not dihydroorotate dehydrogenase (Ura1p), exhibited a reduced mating efficiency when they were co-cultured with wild-type (WT) a cells (Figure 1a). This phenotype was observed in rocking cultures but not in still media (data not shown), suggesting that Cne1p facilitates the conjugation of cells with opposed sexes, not their fusion. In conditions in which WT yeast cells manifested the mitoxantrone (MTX)induced peripheral relocation of vesicles bearing a green fluorescent protein (GFP)-tagged variant of Cne1p (Cne1GFP), cells lacking two subunits of the mating pheromone $\alpha$ factor (i.e., Mfa1 and Mfa2) failed to do so (Figure 1b). ${ }^{25}$ MTX and the $\alpha$ factor triggered the peripheral relocalization of Cne1-GFP with a comparable potency and activated similar signaling pathways. Indeed, the knockout of genes coding for the yeast orthologs of PERK and BCAP31, namely gcn2 and yet3, similarly reduced the relocalization of Cne1-GFP to the cell periphery as triggered by the $\alpha$ factor (Figure 1c) and MTX. ${ }^{25}$ Of note, the knockout of IRE1, coding for a protein involved in the management of ER stress, ${ }^{29}$ induced per se some extent of Cne1-GFP relocalization but did not affect the ability of the $\alpha$ factor to do so (Figure 1c). Altogether, these results suggest that yeast pheromones can induce the exposure of the CRT ortholog Cne1p on the cell surface to stimulate mating.

Essential role of IL-8 in chemotherapy-induced CRT exposure. The $\alpha$ factor signals through a $\mathrm{G}$ protein-coupled receptor (GPCR). ${ }^{30}$ We therefore evaluated the capacity of the pertussis toxin (PTX), a large-spectrum inhibitor of mammalian GPCRs, ${ }^{31}$ to inhibit MTX-induced CRT exposure in cervical carcinoma HeLa cells. PTX was indeed highly efficient at suppressing CRT exposure by HeLa cells responding to MTX or UVC light, as determined by surface immunostaining and flow cytometry or fluorescence microscopy (Figures $2 \mathrm{a}$ and $\mathrm{b}$ ). In line with this notion, PTX compromised the ability of MTX to induce bona fide ICD in murine MCA205 fibrosarcoma cells, as assessed by specific vaccination assays in vivo (Supplementary Figure S1). Next, we downregulated several GPCRs and their ligands by means of specific small-interfering RNAs (siRNAs) and found that the depletion of CXCR1 and its ligand CXCL8 (best known as IL-8) inhibit CRT exposure as triggered in HeLa cells by both MTX and UVC light (Figure 2c). These results were confirmed by a screen in which we evaluated a siRNA library to identify genes that are required for CRT exposure, validating the essential role of CXCL8 in the immunogenic translocation of CRT to the cell surface (Figures $3 a$ and b). In a further series of experiments, we determined whether CXCL8 would be sufficient to induce CRT exposure on human cancer cells. Indeed, recombinant CXCL8 (rCXCL8), but not rCXCL2, promoted the exposure of CRT on the surface of HeLa cells in a time and dose-dependent manner as efficiently as MTX did, an effect that was blocked by the broad-spectrum caspase inhibitor Z-VAD-fmk (Figures 3c-e) as well as by siRNA-mediated depletion of caspase-8 (Supplementary Figure S2). The depletion of several other factors that have previously been shown to be required for CRT exposure as induced by $\mathrm{MTX}^{16}$ also inhibited the 

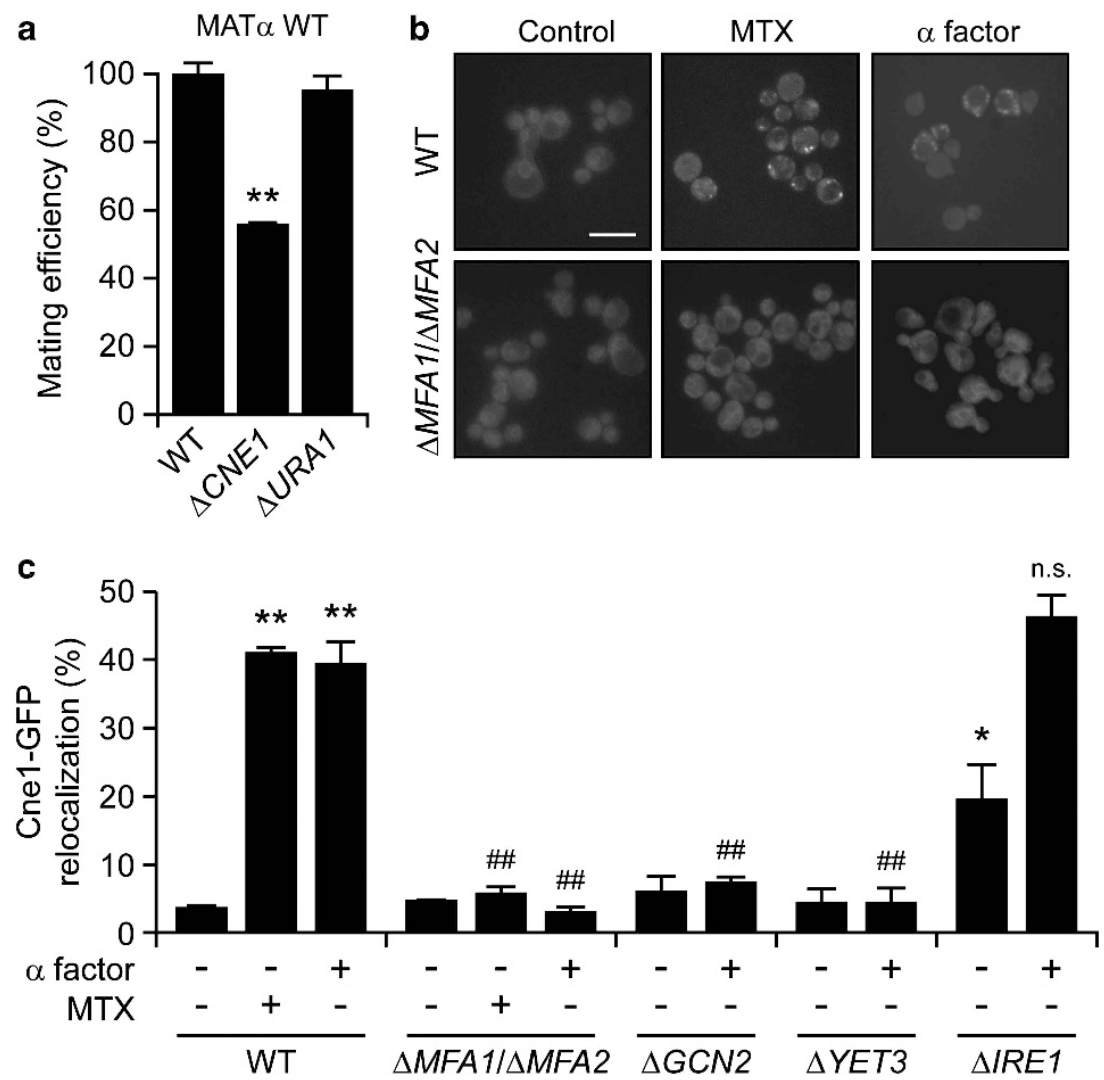

Figure 1 Impact of the yeast $\alpha$ factor on Cne1p exposure and mating. (a) Relative mating efficiency of WT Saccharomyces cerevisiae MAT $\alpha$ BY4742 cells co-cultured with WT, $\Delta$ cne 1 or $\Delta$ ura1 MATa BY4741 cells, as determined via clonogenic mating assay. Mating efficiency of WT BY4741 cells was set to $100 \%$. Data are means \pm S.E.M. $\left(n \geqslant 3 ;{ }^{* *} P<0.01\right.$, as compared with WT BY4741 cells). (b and c) Exponentially growing WT, $\Delta$ mfa1/ $\Delta$ mfa2, $\Delta$ gcn2, $\Delta$ yet3 or $\Delta$ ire 1 BY4741 cells expressing Cne1-GFP were left untreated or treated with $10 \mu \mathrm{M}$ MTX or $100 \mu \mathrm{M} \alpha$ factor for $4 \mathrm{~h}$, followed by the assessment of Cne1-GFP localization by fluorescence microscopy. Representative pictures (scale bar $=10 \mu \mathrm{m}$ ) and quantitative data (means \pm S.E.M.; $n=3$, with $\geqslant 1000$ cells per sample; ${ }^{*} P<0.05,{ }^{* *} P<0.01$, as compared with untreated WT cells; ${ }^{\# \#} P<0.01$, $\mathrm{NS}=$ non significant, as compared with equally-treated WT cells) are reported in panels (b) and (c), respectively

translocation of CRT to the outer leaflet of the plasma membrane as stimulated by rCXCL8. In particular, this applied to the ER stress kinase PERK, its substrate elF2 $\alpha$, the pro-apoptotic BCL-2 family members BAX and BAK (especially when co-depleted) as well as to the SNAREs SNAP25 and VAMP1 (Figure 3f). Conversely, CRT exposure by HeLa cells responding to rCXCL8 was not influenced by the depletion of the essential autophagic factor Beclin 1 (Supplementary Figure S2). Moreover, HeLa cells exposed to rCXCL8 did not manifest signs of autophagy, such as the aggregation of a fluorescent GFP-LC3 chimera into cytoplasmic dots, nor did they release ATP (Supplementary Figure S3). These data indicate that CXCL8 stimulates CRT exposure by a mechanism that does involve autophagy and the ICD-associated, autophagy-dependent ATP release. Rather, CXCL8 appears to activate a CRT exposure pathway that largely overlaps with that ignited by immunogenic chemotherapy.

As CXCL8 turned out to be required for the exposure of CRT triggered by anthracyclines, we wondered whether the knockdown of the murine receptors for $\mathrm{Cxcl} 2$ (the murine CXCL8 ortholog), i.e., Cxcr1 and Cxcr2, would impair the immunogenicity of MTX-induced cell death. To address this question, murine CT26 colon carcinoma or MCA205 fibrosarcoma cells were subjected to the siRNA-mediated downregulation of Cxcr1 or Cxcr2, treated with MTX for $24 \mathrm{~h}$, and then used in vaccination experiments. In this setting, the knockdown of Cxcr1 or Cxcr2 did not affect the ability of MTX to kill cancer cells, yet limited its capacity to stimulate the exposure of CRT on the plasma membrane (data not shown). For vaccination experiments, dying CT26 and MCA205 cells were injected s.c. into the flank of histocompatible, immunocompetent mice (BALB/c and $\mathrm{C} 57 \mathrm{BI} / 6$ animals, respectively), which were re-challenged 1 week later with live, untreated cells of the same type. Of note, the knockdown of Cxcr1 or Cxcr2 significantly reduced the capacity of dying tumor cells to elicit a protective immune response (Figure 4). These results underscore the contribution of the CXCL8 signaling pathway to CRT exposure induced by anthracyclines such as MTX.

Production of CXCL8 by cancer cells in response to chemotherapy. If CXCL8 and its receptors were required for the exposure of CRT on the cell surface in response to immunogenic chemotherapy, one would expect that MTXtreated cancer cells produce CXCL8 in amounts that suffice to elicit autocrine/paracrine signaling pathways. Indeed, both cervical carcinoma HeLa cells and colorectal carcinoma HCT 116 cells responding to MTX (but not to cisplatin) produced 

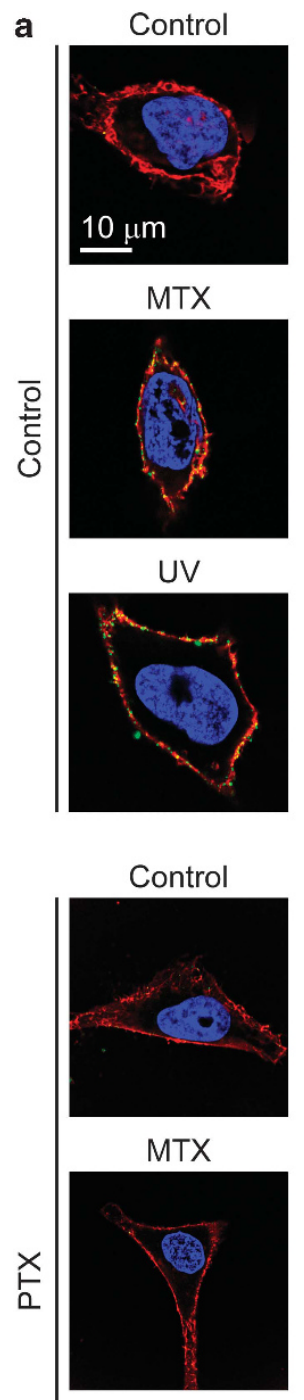

UV

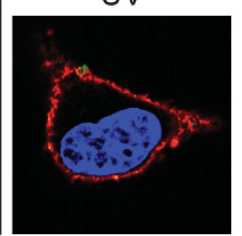

Hoechst 33342 CRT WGA

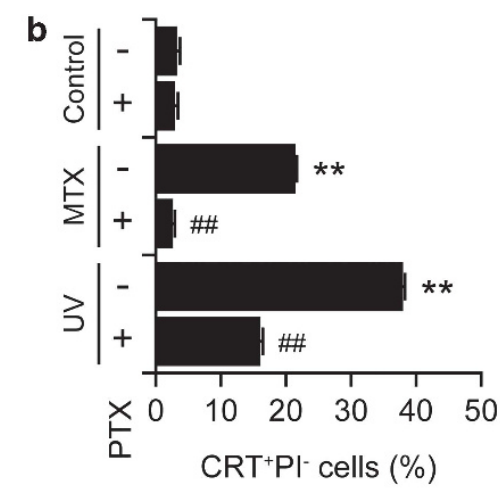

C
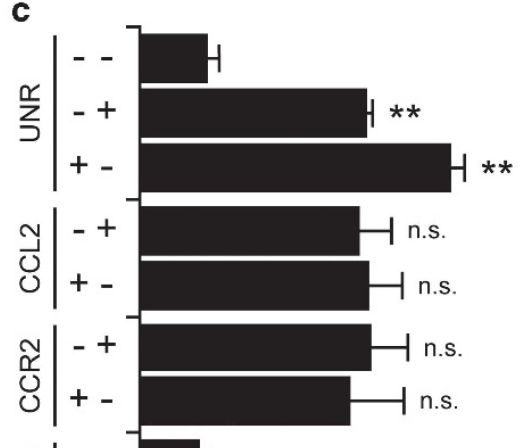
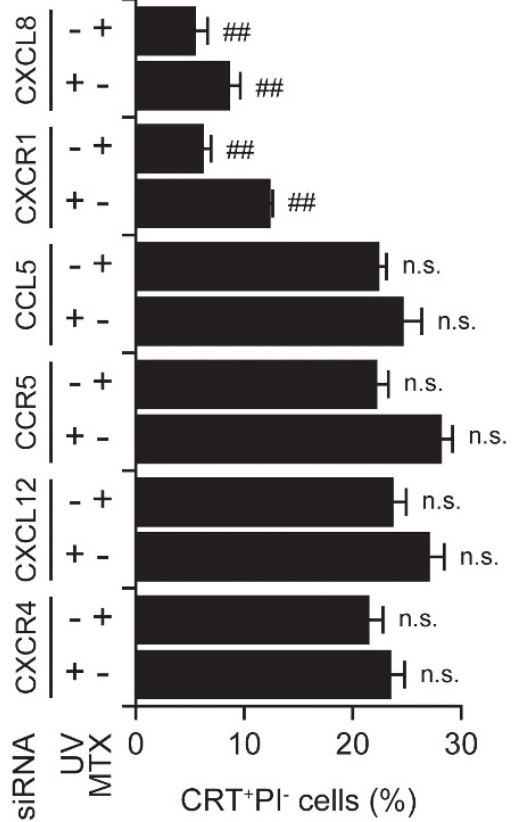

Figure 2 Contribution of chemokine signaling to CRT exposure as triggered by ICD inducers. (a and $\mathbf{b})$ Human cervical carcinoma HeLa cells were treated with $100 \mathrm{ng} / \mathrm{ml} \mathrm{PTX}$ for $30 \mathrm{~min}$ and washed extensively (a and $\mathbf{b}$ ). Alternatively, HeLa cells were transfected with a control siRNA (UNR) or with siRNA targeting the indicated chemokines and chemokine receptors for $48 \mathrm{~h}$ (c). Thereafter, cells were treated with either $1 \mu \mathrm{M} \mathrm{MTX}$ or $100 \mathrm{~J} / \mathrm{cm}^{2} \mathrm{UVC}$ light and $-4 \mathrm{~h}$ later - processed for the confocal microscopy-assisted (a) or flow cytometry-assisted (b and $\mathbf{c}$ ) detection of surface-exposed CRT. Representative pictures (scale bar $=10 \mu \mathrm{m}$ ) and quantitative data on the percentage of live (excluding $\mathrm{PI}, \mathrm{PI}^{-}$) cells exposing CRT on their surface (means \pm S.E.M.; $n=3$; ${ }^{* *} P<0.01$, as compared with untransfected or UNR-transfected untreated cells; ${ }^{\# \#} P<0.01, \mathrm{NS}=$ non significant, as compared with untransfected cells treated with MTX or UV only, or to equally treated UNR-transfected cells) are reported in panels (a) and (b and $\mathbf{c}$ ) respectively

significant levels of CXCL8, as monitored by enzyme-linked immunosorbent assay (ELISA; Figures $5 \mathrm{a}$ and b). Along similar lines, both murine MCA205 fibrosarcoma cells and mouse embryonic fibroblasts secreted the mouse CXCL8 ortholog $\mathrm{Cxcl} 2$ following the administration of MTX, but not of cisplatin (Figures 5c and d). Of note, CXCL8 secretion by HeLa cells responding to MTX occurred well before early (i.e., exposure of phosphatidylserine residues on cell surface) and late (i.e., permeabilization of the plasma membrane) manifestations of apoptosis ${ }^{32}$ (Supplementary Figure S4).

Next, to investigate the possible relevance of these observations in vivo, we performed a vast transcriptome profiling study on CT26 carcinomas and MCA205 fibrosarcomas growing on BALB/c and $\mathrm{C} 57 \mathrm{BI} / 6$ mice, respectively. In this setting, tumor-bearing mice received a systemic chemotherapeutic regimen based on either of two distinct ICD inducers, MTX and oxaliplatin, or on cisplatin, which we used as an internal control. At 6 or $12 \mathrm{~h}$ following chemotherapy, tumors were excised and subjected to quantitative RT-PCR analyses to determine the expression levels of multiple immunologically relevant factors, including a broad collection of chemokines. These analyses revealed that immunogenic (but not non-immunogenic) cell death is preceded by the transcriptional activation of $\mathrm{Cxcl} 2$ (Figure 5e). Hence, chemotherapy with ICD inducers can stimulate the production of the murine CXCL8 ortholog Cxcl2 in vivo.

Enhanced immunogenicity of cell death in the presence of the CXCL8 ortholog Cxcl2. Cisplatin and mitomycin C are unable to induce ICD, correlating with their incapacity to stimulate the translocation of CRT to the cell surface. ${ }^{12-14}$ Based on the aforementioned results, we wondered whether the exogenous administration of $\mathrm{rCxcl} 2$ might compensate for this defect and hence convert cisplatin and mitomycin $\mathrm{C}$ into ICD inducers. To address this question, MCA205 fibrosarcoma cells were treated with cisplatin or mitomycin $\mathrm{C}$, alone or in combination with $\mathrm{rCxcl} 2$, and then injected subcutaneously into $\mathrm{C} 57 \mathrm{BI} / 6$ mice to test their capacity to elicit a protective antitumor immune response. Of note, rCxcl2 did not increase the percentage of MCA205 cells succumbing to cisplatin or mitomycin C (Supplementary Figure S5). However, the combination of $\mathrm{rCxcl} 2$ and cisplatin or mitomycin $\mathrm{C}$ was far more efficient at triggering ICD than either chemotherapeutic alone (Figures 6a-f). Such an immunogenic effect was lost when CRT was depleted by siRNAs, underscoring its essential contribution. Altogether, these findings indicate that the CXCL8 ortholog Cxcl2 can stimulate ICD in the context of chemotherapy.

\section{Discussion}

The pre-apoptotic exposure of CRT at the cell surface has emerged as an important hallmark of ICD, meaning that it can predict - at least in part - the capacity of dying cells to elicit a protective anticancer immune response, both in rodent models ${ }^{2,13,14,17,18,33,34}$ and in patients. ${ }^{35-37}$ Here, we report the unexpected finding that CRT exposure is regulated not only by cell-intrinsic mechanisms, but also by soluble factors that operate in an autocrine/paracrine manner. 
a

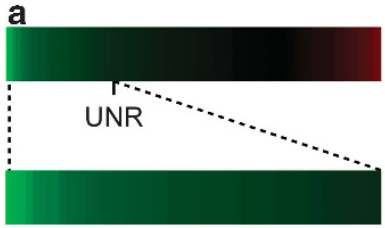

Overall inhibition
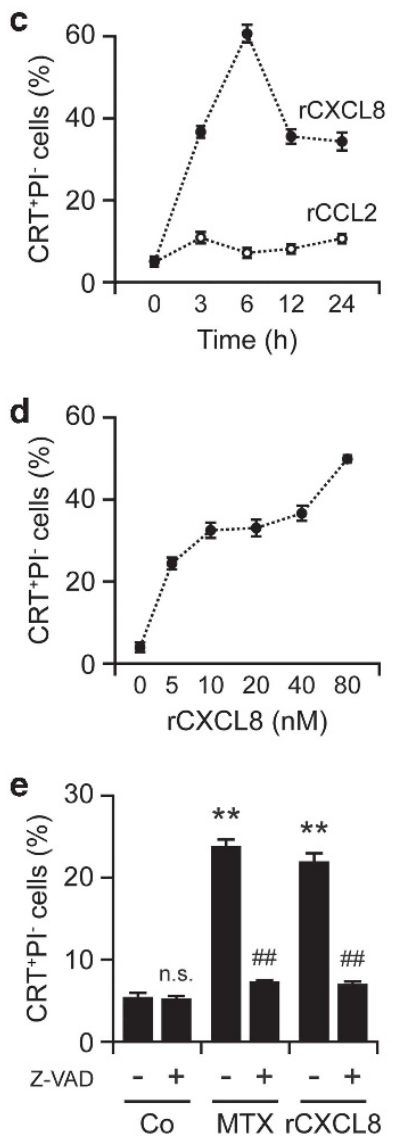

b

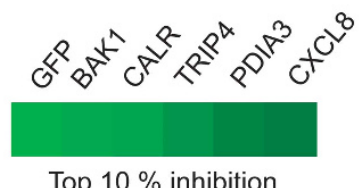

f

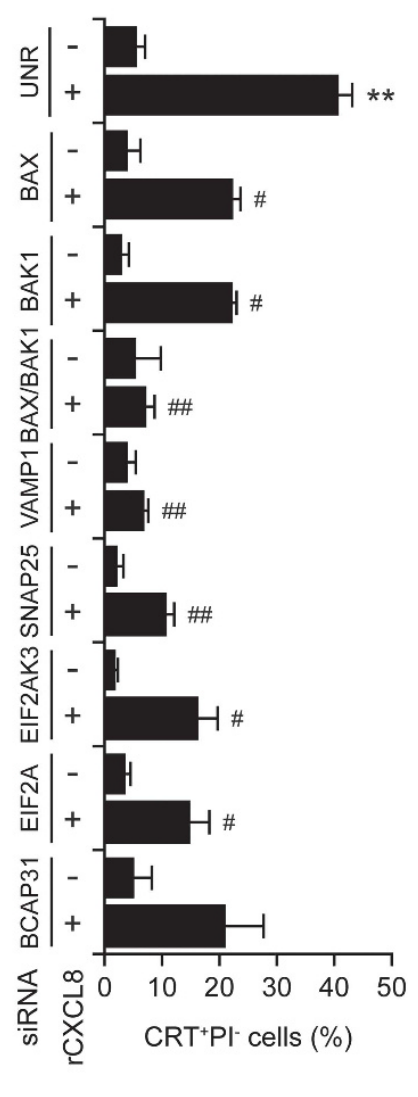

Figure 3 Autocrine/paracrine CXCL8 signaling and CRT exposure. (a and $\mathbf{b}$ ) Human osteosarcoma U2OS cells stably expressing CRT-GFP were reversetransfected with a control siRNA (UNR) as well as with a panel of siRNA targeting 250 proteins involved in cell stress and cell death signaling for $48 \mathrm{~h}$, followed by the administration of $1 \mu \mathrm{M} \mathrm{MTX}$ for additional $4 \mathrm{~h}$ and the automated fluorescence microscopy-assisted acquisition of images for the assessment of CRT-GFP exposure. The modulation of CRT-GFP exposure is depicted in a color code (green = reduction, red $=$ increase), and the siRNAs mediating inhibitory effects in the top 10 percentile are listed. (c-e). Human cenvical carcinoma HeLa cells were treated with $80 \mathrm{ng} / \mathrm{ml} \mathrm{rCXCL8}$ or rCCL2 for the indicated time (c) or with the indicated concentrations of rCXCL8 for $8 \mathrm{~h}$ (d). Alternatively, HeLa cells were left untreated or treated with $50 \mu \mathrm{M}$ z-VAD-fmk for $15 \mathrm{~min}$, and then either kept in control (Co) culture conditions or administered with $1 \mu \mathrm{M}$ MTX or $80 \mathrm{ng} / \mathrm{ml}$ rCXCL8 for additional $8 \mathrm{~h}$ (e). Subsequently, cells were processed for the flow cytometry-assisted detection of surface-exposed CRT. Quantitative data on the percentage of live (excluding $\mathrm{PI}, \mathrm{Pl}^{-}$) cells exposing CRT on their surface (means \pm S.E.M.; $n=3 ;{ }^{* *} P<0.01$, NS $=$ non significant, as compared with untreated cells; ${ }^{\# \#} P<0.01$, as compared with cells receiving MTX or rCXCL8 only) are reported. (f) HeLa cells were transfected with either a control siRNA (UNR) or with siRNAs targeting the indicated proteins for $48 \mathrm{~h}$, and then left untreated or administered with $80 \mathrm{ng} / \mathrm{ml} \mathrm{rCXCL8}$ for $8 \mathrm{~h}$. Finally, CRT exposure was assessed by surface immunostaining and flow cytometry. Quantitative data on the percentage of live (excluding $\mathrm{PI}, \mathrm{PI}^{-}$) cells exposing CRT on their surface (means \pm S.E.M.; $n=2$; ${ }^{\star *} P<0.01$, as compared with untreated UNR-transfected cells; ${ }^{\#} P<0.05,{ }^{\# \#} P<0.01$ as compared with equally treated UNR-transfected cells) are reported
When a haploid $S$. cerevisiae cell is ready to mate, it secretes pheromones that signal cells of the opposite mating type to stop proliferating and prepare for sexual reproduction. The fusion of two haploid cells of opposite mating types generates a diploid cell that subsequently undergoes meiosis, generating haploid cells with new genetic assortments. ${ }^{38}$ Here, we report that yeast pheromones can stimulate the relocalization of the CRT ortholog Cne1p to the cell periphery, and that Cne1p is required for optimal mating, in particular in shaking cultures (in which stable intercellular contacts are rather difficult to be achieved). Our results indicate that Cne1p is not absolutely required for mating but facilitates cell-to-cell conjugation, in line with previous observations on the role of surface-exposed CRT in the fertilization of oocytes by sperm cells. $^{21-24}$ These findings point to the existence of phylogenetically conserved mechanisms for sexual reproduction and suggest that common factors (such as CRT and polyamines) may have similar roles in improving fertility across phyla. ${ }^{39}$

Translating our findings from yeast to the mammalian system, we discovered that a series of soluble factors acting on GPCRs (which structurally resemble the yeast pheromone receptor) facilitate the immunogenic exposure of CRT. Thus, several chemokines including human CXCL8 and its mouse ortholog $\mathrm{Cxcl} 2$ are endowed with the ability to stimulate CRT exposure in cancer cells by acting on the receptors CXCR1/ Cxcr1 and CXCR2/Cxcr2. As the mammalian genome encodes several hundred GPCRs, ${ }^{40}$ we suspect that other ligands and receptors of the same class may be involved in this process. Future studies should explore this possibility in a systematic manner.

CXCL8 and other chemokines are often produced by cancer cells in a constitutive manner, acting as autocrine/ paracrine growth factors and stimulating local inflammatory and immune responses. These mediators operate in a strictly context-dependent manner, meaning that their relationship to oncogenesis, cell-autonomous oncosuppression (by senescence or apoptosis), tumor progression, the epithelialmesenchymal transition and immunosurveillance is highly complex. ${ }^{41,42}$ For instance, an elevated production of CXCL8 characterizes the so-called 'senescence-associated secretory phenotype', meaning that senescent tumor cells or tumor-associated fibroblasts can generate an extracellular microenvironment rich in CXCL8. ${ }^{43}$ In addition, breast cancer cells reportedly can escape from the therapeutic inhibition of the phosphoinositide-3-kinase/mammalian target of rapamycin (PI3K/mTOR) signaling cascade by upregulating CXCL8 and hence activating alternative growth-stimulatory pathways. ${ }^{44}$ Of note, high expression levels of CXCL8 or CXCR2 have been associated with worsened disease outcome in several types of cancer, including astrocytomas and lung adenocarcinoma. ${ }^{45,46}$

Thus, it may appear paradoxical that the CXCL8/CXCR1-2 system is often constitutively active in cancer cells, mainly mediating pro-tumorigenic effects, yet can be hyperactivated by immunogenic chemotherapy to promote CRT exposure and ICD. Previous studies have shown that radiotherapy can also stimulate CXCL8 production, ${ }^{47}$ in line with the fact that both $\gamma$ and UV rays induce CRT-dependent ICD. ${ }^{5,11}$ Local radiotherapy can indeed mediate so-called 'abscopal' effects. These consist in the regression of distant non-irradiated 

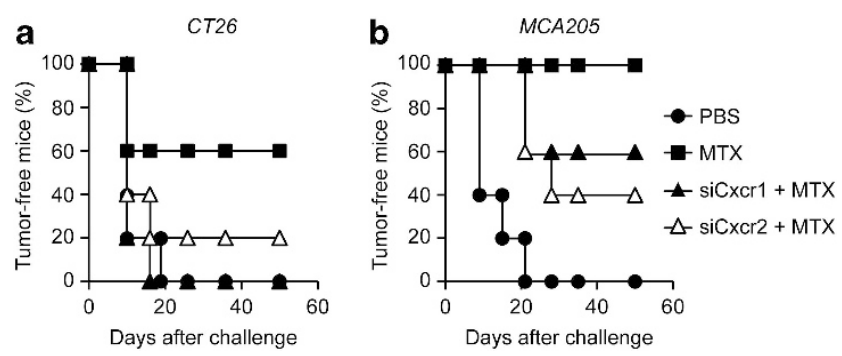

Figure 4 Impact of CXCL8 on anticancer immune responses elicited in vivo by ICD. (a and b) Immunocompetent BALB/c ( $n=10$ per group) or C57BI/6 ( $n=5$ per group) mice were inoculated s.c. with CT26 or MCA205 cells, respectively, which had previously been left untransfected or transfected with siRNAs targeting Cxcr1 or Cxcr2 for $48 \mathrm{~h}$ and then treated with $2 \mu \mathrm{M}$ MTX for $20 \mathrm{~h}$. PBS was used as a negative control condition. Seven days later, all mice were re-challenged with live CT26 or MCA205 cells and tumor incidence was routinely monitored. Kaplan-Meier curves depict the percentage of tumor-free mice over time

lesions or metastases, presumably reflecting a systemic anticancer immune response that results from the immunogenic death of malignant cells belonging to the (irradiated) primary tumor mass. ${ }^{48}$ Nevertheless, the putative functional implication of CXCL8 in the abscopal effects of radiotherapy needs to be investigated in more detail.

The first immunotherapeutic anticancer regimen to be introduced into the clinical routine was based on the intravesical instillation of the bacillus Calmette-Guérin (BCG), a live attenuated form of Mycobacterium bovis, shortly after the transurethral resection of superficial urothelial carcinoma. ${ }^{49,50}$ This treatment is particularly efficient when pre-existing BCG-specific T cells are primed for interferon $\gamma$ production, presumably within residual tumor lesions or draining lymph nodes. ${ }^{51}$ In this context, the urinary concentration of CXCL8 has turned out to constitute an early biomarker of subsequent immune responses and to predict therapeutic outcome. ${ }^{52}$ BCG induces the apoptotic death of bladder cancer cells either directly or through the activation of humoral or cellular immune effectors, ${ }^{53}$ suggesting that, by promoting ICD, CXCL8 might have a decisive role in the therapeutic efficacy of BCG-based immunotherapy.

In conclusion, our work unravels an unsuspected contribution of chemokines to CRT exposure and ICD as elicited by immunogenic chemotherapeutics. We surmise that this finding may have major implications for the comprehension of anticancer immune responses as well as for their therapeutic modulation.

\footnotetext{
Materials and Methods

Chemicals and cell cultures. Unless otherwise noted, chemicals were purchased from Sigma-Aldrich (St. Louis, MO, USA), cell culture media and supplements from Life Technologies (Carlsbad, CA, USA) and plasticware from Corning Life Sciences (Corning, NY, USA). Human cervical carcinoma HeLa cells, human osteosarcoma U2OS cells and their derivatives were grown in Dulbecco's modified Eagle's medium (DMEM) supplemented with $10 \%$ fetal bovine serum (FBS), 100 units $/ \mathrm{ml}$ penicillin G sodium and $100 \mu \mathrm{g} / \mathrm{ml}$ streptomycin sulfate. Human colon carcinoma HCT 116 cells were maintained in McCoy's 5A medium supplemented as above. Murine fibrosarcoma MCA205 and murine colon carcinoma CT26 cells were cultured in RPMI-1640 medium supplemented as above. Mouse embryonic fibroblasts were grown in DMEM supplemented with $10 \%$ FBS, non-essential amino acids, 100 units/ml penicillin G sodium and $100 \mu \mathrm{g} /$ $\mathrm{ml}$ streptomycin sulfate. HeLa cells engineered for the stable expression of a
}

GFP-LC3 chimera were maintained in the presence of $200 \mu \mathrm{g} / \mathrm{ml}$ geneticin while U2OS cells stably co-expressing a histone 2B-red fluorescent protein (H2B-RFP) fusion and a CRT-GFP chimera ${ }^{13}$ were cultured in the continuous presence of $200 \mu \mathrm{g} / \mathrm{ml}$ zeocine plus $1 \mu \mathrm{g} / \mathrm{ml}$ blasticidine. Z-VAD-fmk was obtained from Bachem (Basel, Switzerland), whereas $\mathrm{rCXCL}, \mathrm{rCCL} 2$ and $\mathrm{rCxCl2}$ were purchased from (R\&D Systems, Minneapolis, MN, USA).

Yeast strains. The haploid WT Saccharomyces cerevisiae strains BY4741

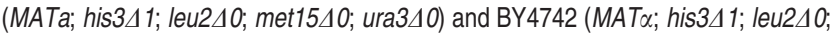
lys2 $\Delta 0$; ura3 $\Delta 0$ ), as well as the $\Delta c n e 1$ and $\Delta u r a 1 B Y 4741$ mutants used in this study were obtained from Euroscarf (Frankfurt, Germany). The $\Delta m f a 1 / m f a 2$ strain was generated by deleting mfa2 in $\Delta m f a 1$ BY4741 cells, followed by the GFP tagging of cne1 via standard procedures. ${ }^{54}$ The $\Delta g c n 2, \Delta y e t 3$ and $\Delta$ ire 1 BY4741 strains used for Cne1-GFP translocation studies have previously been described. $^{25}$

Yeast culture. For the evaluation of mating efficiency, yeast strains were grown $\left(\right.$ at $28{ }^{\circ} \mathrm{C}$ ) on yeast extract peptone dextrose (YEPD) medium containing $1 \%$ yeast extract, $2 \%$ peptone and $2 \%$ D-glucose and processed as described below. For Cne1-GFP translocation studies, yeast strains were cultured (at $28{ }^{\circ} \mathrm{C}$ ) in synthetic complete (SC) medium containing $0.17 \%$ yeast nitrogen base (BD Biosciences, Franklin Lakes, $\mathrm{NJ}, \mathrm{USA}), 0.5 \%\left(\mathrm{NH}_{4}\right)_{2} \mathrm{SO}_{4}, 30 \mathrm{mg} / \mathrm{l}$ amino acids but histidine ( $80 \mathrm{mg} / \mathrm{l})$ and leucine $(200 \mathrm{mg} / \mathrm{l}), 30 \mathrm{mg} / \mathrm{l}$ adenine, $320 \mathrm{mg} / \mathrm{l}$ uracil and $2 \%$ glucose (as carbon source). Two percent agar was added to obtain solid media.

Microscopic evaluation of Cne1-GFP relocalization. Exponentially growing yeast cultures were split into aliquots and treated with $10 \mu \mathrm{M}$ MTX or $100 \mu \mathrm{M} \alpha$ factor for $4 \mathrm{~h}$. Thereafter, the intracellular localization of Cne1-GFP was analyzed by means of an Axioskop fluorescence microscope (Zeiss, Wetzlar, Germany) equipped with an eGFP-specific bandpass filter.

Yeast mating efficiency. To determine mating efficiency, $1 \times 10^{7}$ BY4742 (MAT $\alpha$ ) cells were mixed with $2 \times 10^{6}$ WT BY4741 (MATa), $\Delta c n e 1$ BY4741 (MATa) or Sura1 BY4741 (MATa) cells in $20 \mathrm{ml}$ YEPD medium. Cultures were agitated for $3 \mathrm{~h}$ and aliquots were seeded on agar plates containing different media. Thus, (i) the amount of viable haploid BY4741 and diploid cells was assessed by plating 500 cells from co-cultures on SC agar plates containing all amino acids except lysine, and (ii) the amount of viable diploid cells was determined by plating 2000 cells from co-cultures on SC agar plates containing all amino acids except lysine and methionine. After incubation for 2 days at $28^{\circ} \mathrm{C}$, colony-forming units (CFUs) were enumerated and mating efficiency was determined as the ratio between diploid and diploid plus haploid BY4741 MATa CFUs.

RNA interference. RNA interference experiments were performed by transfecting cells with a non-targeting control siRNA (herein referred to as UNR, sense $5^{\prime}$-GCCGGUAUGCCGGUUAAGUdTdT-3'), with siRNAs specific for BAK1 (sense 5'-GCGAAGUCUUUGCCUUCUCdTdT-3'), BAX (sense 5'-GGGUUUCAU CCAGGAUCGAdTdT-3'), BECN1 (sense 5'-CUCAGGAGAGGAGCCAUUUdT dT-3'), BCAP31 (sense 5'-GCGCGAAAUUCGGAAGUAUdTdT-3'), CASP8 (sense $5^{\prime}$-CAUCUCAGUUCACUGGUUUdTdT-3'), CRT (sense $5^{\prime}$-CCGCUGGGUCG AAUCCAAAdTdT-3'), CCL2 (sense $5^{\prime}$-GCAGAAGUGGGUUCAGGAUdTdT-3'), CCL5 (sense $5^{\prime}$-GGUUCGGGAGUACAUCAACdTdT-3'), CCR2 (sense $5^{\prime}$-GU AAUGAUGUCGUUUGAAUdTdT-3'), CCR5 (sense $5^{\prime}$-GUCAGUAUCAAUUCUG GAAdTdT-3'), CXCL8 (sense $5^{\prime}$-GCGCCAACACAGAAAUUAUdTdT-3'), CXCL12 (sense 5'- CCAUGUAGAAGCCACUAUUdTdT-3'), CXCR1 (sense 5'-GCGUCA CUUGGUCAAGUUUdTdT-3'), CXCR4 (sense 5'-GGAAGCUGUUGGCUGAA AAdTdT-3'), elF2 $\alpha$ (sense $5^{\prime}$-GAAACUGAAAGCAAUCGAAdTdT-3'), PERK (sense $5^{\prime}$-CUCACAGGCAAAGGAAGGAGdTdT-3'), SNAP25 (sense 5'-CAGGC AUUGCACUAAAAGUdTdT-3') or VAMP1 (sense $5^{\prime}$-GGACAUCAUGCGUGUG AAUdTdT- $3^{\prime}$ ), all obtained from Sigma-Aldrich; or with commercial siRNA pools targeting Cxcr1 or Cxcr2 (Dharmacon, Waltham, MA, USA). siRNAs were transfected by means of the HiPerfect transfection reagent (Qiagen, Hilden, Germany), as previously described. ${ }^{55,56}$

siRNA array screening. Bio-one $\mu$ Clear 384-well plates (Greiner Bio One, Kremsmuenster, Austria) were printed with $3.125 \mathrm{ng}$ individual siRNAs (Qiagen) designed to target 250 different human proteins implicated in cell death and stress-response pathways. siRNA positioning was randomized to minimize spatial 

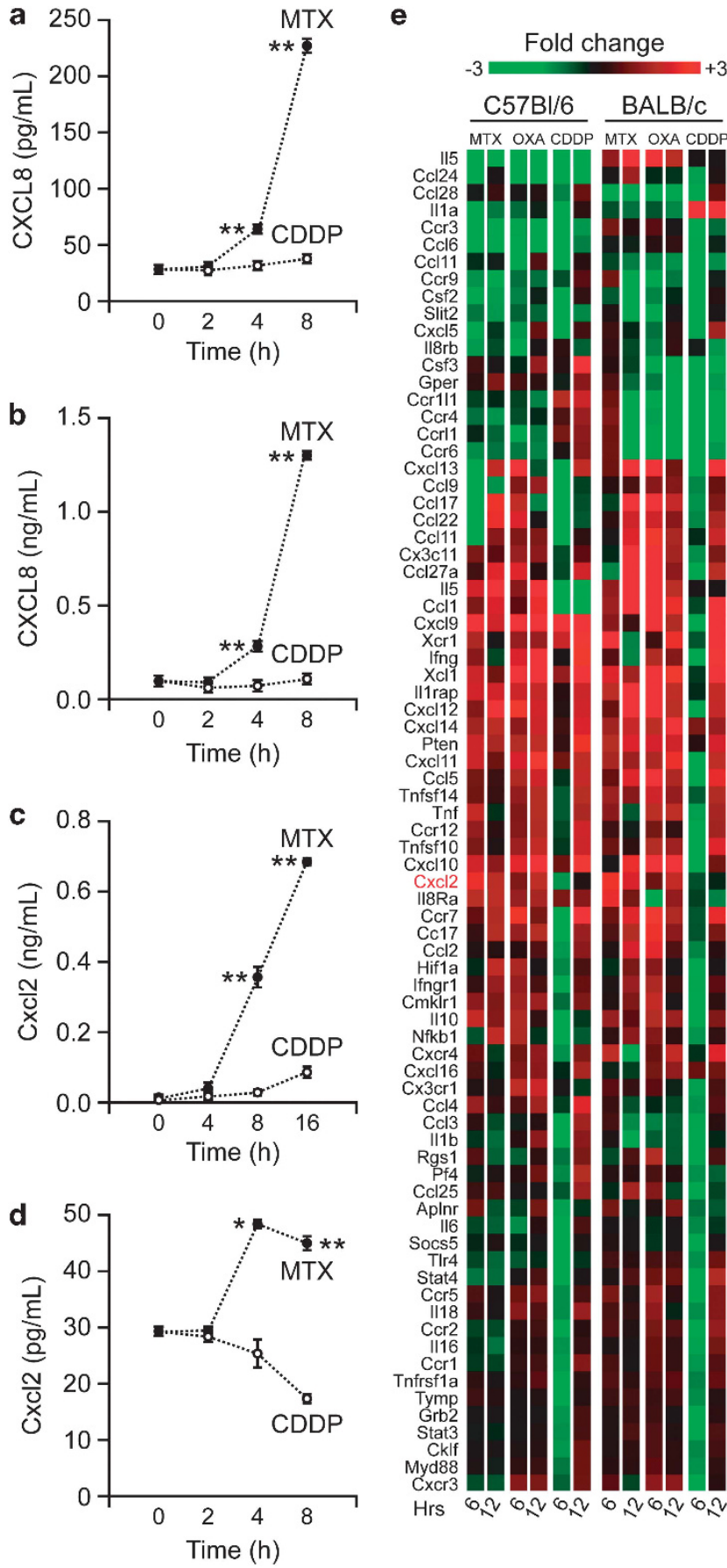

Figure 5 Release and transcriptional regulation of CXCL8 and CXCl2 in the course of ICD. (a-d) Human cervical carcinoma HeLa cells (a), human colorectal carcinoma HCT 116 cells (b), murine fibrosarcoma MCA205 cells (c) and mouse embryonic fibroblasts (d) were treated with 75 (a, b and d) or 150 (c) $\mu \mathrm{M}$ cisplatin (CDDP) or with $2(\mathbf{a}, \mathbf{b}$ and $\mathbf{d})$ or 4 (c) $\mu \mathrm{M}$ MTX for the indicated time, followed by the analysis of culture supernatants for CXCL8 (a and $\mathbf{b}$ ) and $\mathrm{Cxc} 2$ ( $\mathbf{c}$ and $\mathbf{d})$ levels. Quantitative data (means \pm S.E.M.; $n=3 ;{ }^{*} P<0.05$, ${ }^{\star \star} P<0.01$, as compared with CDDP-treated cells) are reported. (e) Immunocompetent BALB/C or C57BI/6 mice bearing established СT26 colon carcinomas and MCA205 fibrosarcomas, respectively, were treated with $5.17 \mathrm{mg} / \mathrm{kg}$ MTX, $10 \mathrm{mg} / \mathrm{kg}$ oxaliplatin (OXA) or $0.25 \mathrm{mg} / \mathrm{kg}$ cisplatin (CDDP) for 6 or $12 \mathrm{~h}$, followed by the recovery of tumors and their processing for quantitative RT-PCR analyses. Average fold changes as determined on $n=3$ independent experiments are depicted effects. For each gene, two distinct siRNAs were chosen, favoring experimentally verified siRNAs that were identified on the GeneGlobe Search Center (Qiagen). After printing, plates were dehydrated, sealed and stored at $-20^{\circ} \mathrm{C}$ until usage. Reverse transfection was performed by means of the HiPerfect Transfection Reagent on re-hydration of siRNAs with $5 \mu \mathrm{l}$ OptiMEM (Life Technologies), according to the manufacturer's instructions. In this setting, $2 \times 10^{3}$ U2OS cells stably co-expressing H2B-RFP and CRT-GFP were seeded in each well and maintained for $48 \mathrm{~h}$ before the administration of $1 \mu \mathrm{M}$ MTX for additional $4 \mathrm{~h}$. Eventually, cells were fixed in 4\% paraformaldehyde (w/v in PBS) for $20 \mathrm{~min}$ at room temperature, washed and stored in PBS at $4{ }^{\circ} \mathrm{C}$ until imaging. Four view fields per well were acquired by means of a BD Pathway 855 automated bioimager (BD Biosciences) equipped with a UApo/340 20X/0.75 objective (Olympus, Center Valley, PA, USA). Subsequently, images were segmented and analyzed for GFP granularity by using the AttoVision software v. 1.7 (BD Biosciences). Finally, data were mined and statistically evaluated using the Prism software v. 5 (Graph Pad software Inc., La Jolla, CA, USA).

Automated evaluation of autophagy. Autophagy was monitored by automated fluorescence microscopy. To this aim, $5 \times 10^{3}$ GFP-LC3-expressing HeLa cells were seeded in 96-well Black/Clear imaging plates (BD Biosciences) and allowed to adapt for $24 \mathrm{~h}$. Thereafter, cells were treated with $40,80,160$ or $320 \mathrm{ng} / \mathrm{ml} \mathrm{rCXCL8}$ or $1 \mu \mathrm{M}$ rapamycin for up to additional $24 \mathrm{~h}$, fixed in $4 \%$ paraformaldehyde (w/v in PBS) supplemented with $1 \mu \mathrm{M}$ Hoechst 33342 (Life Technologies) for $20 \mathrm{~min}$ at room temperature, and processed for imaging as described above. Images were segmented and analyzed for the number of GFP ${ }^{+}$ dots per cell by means of the AttoVision software v. 1.7.

ATP release assay. To quantify ATP release in the course of ICD, WT HeLa cells growing in 12- or 24-well plates were treated with $40,80,160$ or $320 \mathrm{ng} / \mathrm{ml}$ rCXCL8 or $2 \mu \mathrm{M}$ MTX for $24 \mathrm{~h}$, and then stained with $1 \mu \mathrm{M}$ quinacrine plus $1 \mu \mathrm{g} / \mathrm{ml}$ propidium iodide (PI, Life Technologies) for $30 \mathrm{~min}$ at $37^{\circ} \mathrm{C}$. Thereafter, quinacrine fluorescence was monitored on a FACScan or FACScalibur cytofluorometer (BD Biosciences). First-line statistical analyses - limited to live $\left(\mathrm{PI}^{-}\right)$cells - were performed by means of the Cell Quest Software package (BD Biosciences). Alternatively, extracellular ATP levels were measured by the luciferin-based ENLITEN ATP Assay (Promega, Madison, WI, USA). In this setting, ATP-driven chemoluminescence was recorded on a FLUOstar OPTIMA FL Plate Reader (BMG Labtech, Offenburg, Germany).

Determination of surface-exposed CRT. CRT exposure was assessed by surface immunostaining and flow cytometry or fluorescence microscopy, as previously described. ${ }^{3,57}$ In brief, cells growing on standard supports were collected, washed twice with PBS and fixed in $0.25 \%$ paraformaldehyde ( $w / v$ in PBS) for $5 \mathrm{~min}$ at RT. Alternatively, cells grown on coverslips were washed and similarly fixed. After two additional washes in cold PBS, cells were incubated with an anti-CRT antibody (ab2907, Abcam, Cambridge, UK) diluted in cold blocking buffer ( $2 \%$ FBS, v/v in PBS) for 30 min on ice, washed and incubated for additional 30 min with an anti-rabbit AlexaFluor 488 conjugate (Life Technologies) in blocking buffer. For fluorescence microscopy studies, $5 \mu \mathrm{g} / \mathrm{ml}$ AlexaFluor 633-conjugated wheat germ agglutinin (Life Technologies) was added to visualize the plasma membrane. Finally, samples were washed in cold PBS, incubated with $1 \mu \mathrm{g} / \mathrm{ml} \mathrm{PI}$ for $5 \mathrm{~min}$ and either analyzed on a FACScan cytofluorometer or re-fixed in $3.7 \%$ paraformaldehyde plus $1 \mu \mathrm{g} / \mathrm{ml}$ Hoechst 33342 (Life Technologies), washed, embedded in Fluoromount-G mounting medium (Southern Biotech, Birmingham, AL, USA) and analyzed by means of a TCS SPE confocal microscope (Leica Microsystems $\mathrm{GmbH}$, Wetzlar, Germany), equipped with a $63 \mathrm{X} / 1.15$ objective (Olympus). For cytofluorometric analyses, isotype-matched IgG antibodies (Cell Signaling Technology, Danvers, MA, USA) were used as control conditions, and statistical analyses - limited to live $\left(\mathrm{PI}^{-}\right)$cells - were performed by means of the Cell Quest Software package. ${ }^{58,59}$

Cell death assays. Apoptotic cell death was quantified based on the exposure of phosphatidylserine on the cell surface and plasma membrane permeabilization. ${ }^{59,60}$ To this aim, cells were collected and stained with a fluorescein isothiocianate (FITC)-tagged version of Annexin V plus PI by means of the FITC-Annexin V Apoptosis Detection Kit II (BD Biosciences), as per the manufacturer's instructions. Cytofluorometric acquisitions were performed on a FACScan or FACScalibur cytofluorometer, and first-line statistical analyses were carried out on the Cell Quest Software package. 


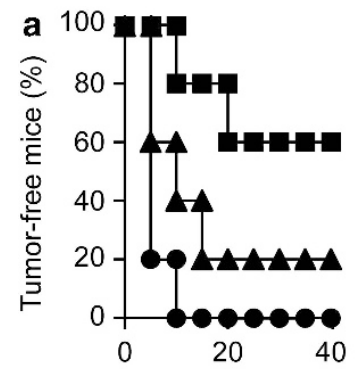

Days after challenge
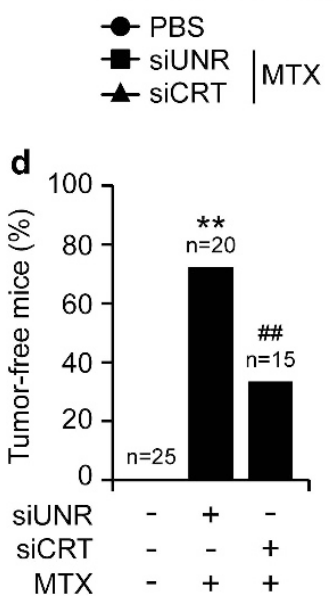

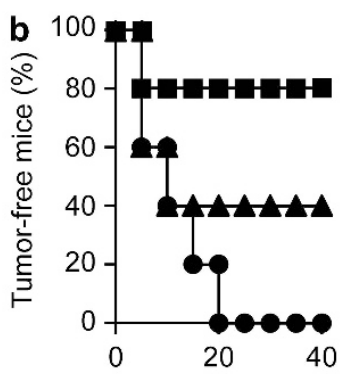

Days after challenge

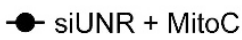

- siUNR |MitoC

- siCRT $\mid \mathrm{rCxcl} 2$

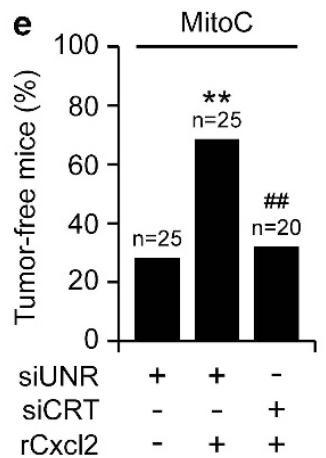

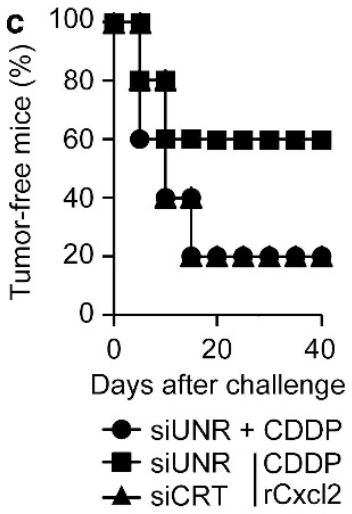

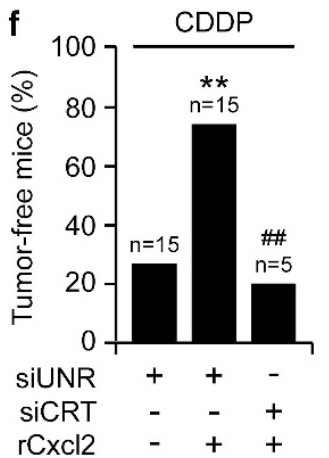

Figure 6 ICD as induced by non-immunogenic chemotherapeutics plus Cxcl2. (a-f) Immunocompetent C57BI/6 mice ( $n=5$ per group) were inoculated s.c. with PBS or murine MCA205 fibrosarcoma cells that had previously been transfected with a control siRNA (siUNR) or with a siRNA targeting CRT (siCRT) and then treated with $2 \mu \mathrm{M}$ MTX, $200 \mu \mathrm{M}$ mitomycin C (MitoC), $150 \mu \mathrm{M}$ cisplatin (CDDP), alone or combined with $80 \mathrm{ng} / \mathrm{ml} \mathrm{rCxcl2,} \mathrm{for} 20 \mathrm{~h}$. Panels (a-c) report Kaplan-Meier curves depicting the percentage of tumor-free mice over time. Panels $(\mathbf{d}-\mathbf{f})$ depict the percentage of tumor free animals at the end of the experiment. The numbers of mice allocated to each group is indicated. ${ }^{* *} P<0.01$, as compared with animals receiving PBS only (d), siUNR-transfected cells treated with MitoC (e) or siUNR-transfected cells treated with CDDP (f); ${ }^{\# \# ~} P<0.01$, as compared with animals receiving siUNR-transfected cells treated with MTX (d), MitoC plus rCxcl2 (e) or CDDP plus rCxcl2 (f)

Immunoblotting. For immunoblotting, approximately $1 \times 10^{6}$ cells were washed with cold PBS and lysed as previously described. ${ }^{55,56}$ Fifty micrograms of proteins were then separated according to molecular weight on NuPAGE Novex Bis-Tris $4-12 \%$ pre-cast gels (Life Technologies) and electrotransferred to nitrocellulose membranes (Bio-Rad, Hercules, CA, USA). Unspecific binding sites were blocked by incubating membranes for $1 \mathrm{~h}$ in $0.05 \%$ Tween 20 ( $/ / \mathrm{v}$ in TBS) supplemented with $5 \%$ non-fat powdered milk, followed by overnight incubation at $4{ }^{\circ} \mathrm{C}$ with primary antibodies specific for BECN1 (Santa-Cruz Biotechnology, Santa Cruz, CA, USA) or CASP8 (Calbiochem-Merck Millipore, Billerica, MA, USA). Equal loading of lanes was monitored by probing membranes with antibodies specific for $\beta$-actin (Millipore-Chemicon International, Temecula, CA, USA). Primary antibodies were detected with appropriate horseradish peroxidase-labeled secondary antibodies (Southern Biotechnologies Associates, Birmingham, UK) and revealed on a ImageQuant LAS 4000 software-assisted imager on incubation with the ECL Plus Western Blotting Detection System (both from GE Healthcare, Piscataway, NJ, USA).

Quantification of extracellular CXCL8 and Cxcl2. The concentration of CXCL8 and Cxcl2 in culture supernatants was measured by means of commercial ELISA kits (Biolegend, San Diego, CA, USA and R\&D Systems), following the manufacturer's instructions. Absorbance was monitored by means of a FLUOstar Optima fluorescence plate reader (BMG Labtech).

Transcriptomic studies. BALB/C or $\mathrm{C} 57 \mathrm{~B} / / 6$ mice were inoculated s.c. with $5 \times 10^{5}$ CT26 cells or $2 \times 10^{5}$ MCA205 cells, respectively. When tumor size reached $40-80 \mathrm{~mm}^{2}$, mice were treated i.p. with $10 \mathrm{mg} / \mathrm{kg}$ oxaliplatin, $0.25 \mathrm{mg} / \mathrm{kg}$ cisplatin or $5.17 \mathrm{mg} / \mathrm{kg} \mathrm{MTX.} \mathrm{Whole} \mathrm{RNA} \mathrm{from} \mathrm{tumor} \mathrm{homogenates} \mathrm{was} \mathrm{extracted}$ using the RNAqueous kit (Life Technologies), following the manufacturer's instructions. Five micrograms RNA from each sample were then reversetranscribed using the High Capacity cDNA Reverse Transcription Kit (Life Technologies), as per the manufacturer's recommendations. Subsequently, gene expression assays were performed using a Mouse Chemokine Gene Set v1.0 custom TaqMan Array Micro Fluidic Card (Life Technologies) and analyzed by means of an ABI Prism 7900HT Sequence Detection System (Life Technologies).

Antitumor vaccination studies. All animal experiments were approved by the local Ethics Committee (CEEA IRCIV/ IGR n`26, registered with the French Ministry of Research), were in compliance with the 63/2010/EU directive from the European Parliament and respected the FELASA guidelines. C57B//6 and BALB/C mice (Charles River Laboratory, Wilmington, MA, USA) were housed in a temperature-controlled environment with 12 -h light-dark cycles and received food and water ad libitum. For vaccination experiments, $3 \times 10^{5}$ MCA205 or $3 \times 10^{6}$ CT26 cells dying in response to MTX, cisplatin or mitomycin C (alone or combined with rCXCL8) were inoculated s.c. into the flank of 6 -week-old female C57BI/6 or BALB/C mice, respectively. Seven days later, C57BI/6 or BALB/C mice were re-challenged in the contralateral flank with $1 \times 10^{5}$ living MCA205 cells or $5 \times 10^{5}$ CT26 cells, respectively, and tumor incidence was routinely monitored for up to 50 days.

Statistical procedures. Unless otherwise indicated, assays were performed in triplicate instances, yielding comparable results. Data (generally are presented as means \pm S.D. or means \pm S.E.M.), were analyzed with Microsoft Excel (Microsoft Co., Redmont, WA, USA). Statistical significance was assessed by paired or unpaired (as appropriate), two-tailed Student's $t$-tests or Pearson's $\chi^{2}$ test, as appropriate. $P$-values $<0.05$ were considered statistically significant.

\section{Conflict of Interest}

The authors declare no conflict of interest. 
Acknowledgements. GK is supported by the European Commission (ArtForce); Agence National de la Recherche (ANR); Ligue Nationale contre le Cancer (Equipe labellisée); Fondation pour la Recherche Médicale (FRM); Institut National du Cancer (INCa); LabEx Immuno-Oncologie; Fondation de France; Fondation Bettencourt-Schueller; AXA Chair for Longevity Research; Cancéropôle lle-de-France and Paris Alliance of Cancer Research Institutes (PACRI). AQS is supported by Fondation ARC pour la recherche sur le cancer. IM is supported by la Ligue Nationale contre le Cancer. We thank SIRIC SOCRATE for their critical support. We are grateful to the Austrian Science Fund FWF (Austria) for grants P23490-B12 and P24381-B20 to FM.

1. Galluzzi L, Vitale I, Abrams JM, Alnemri ES, Baehrecke EH, Blagosklonny $\mathrm{MV}$ et al. Molecular definitions of cell death subroutines: recommendations of the Nomenclature Committee on Cell Death 2012. Cell Death Differ 2012; 19: 107-120.

2. Beneteau M, Zunino B, Jacquin MA, Meynet O, Chiche J, Pradelli LA et al. Combination of glycolysis inhibition with chemotherapy results in an antitumor immune response. Proc Nat Acad Sci USA 2012; 109: 20071-20076.

3. Michaud M, Martins I, Sukkurwala AQ, Adjemian S, Ma Y, Pellegatti $P$ et al Autophagy-dependent anticancer immune responses induced by chemotherapeutic agents in mice. Science 2011; 334: 1573-1577.

4. Yang Y, Li XJ, Chen Z, Zhu XX, Wang J, Zhang LB et al. Wogonin-induced calreticulin annexin $A 1$ exposure dictates the immunogenicity of cancer cells in a PERK/AKTdependent manner. PLoS One 2012; 7: e50811.

5. Kroemer G, Galluzzi L, Kepp O, Zitvogel L. Immunogenic cell death in cancer therapy. Annu Rev Immunol 2013; 31: 51-72.

6. Ma Y, Adjemian S, Mattarollo SR, Yamazaki T, Aymeric L, Yang $\mathrm{H}$ et al. Anticancer chemotherapy-induced intratumoral recruitment and differentiation of antigen-presenting cells. Immunity 2013; 38: 729-741.

7. Denkert C, Loibl S, Noske A, Roller M, Muller BM, Komor M et al. Tumor-associated lymphocytes as an independent predictor of response to neoadjuvant chemotherapy in breast cancer. J Clin Oncol 2010; 28: 105-113.

8. Fridman WH, Pages F, Sautes-Fridman $\mathrm{C}$, Galon J. The immune contexture in human tumours: impact on clinical outcome. Nat Rev Cancer 2012; 12: 298-306.

9. Galluzzi L, Senovilla L, Zitvogel L, Kroemer G. The secret ally: immunostimulation by anticancer drugs. Nat Rev Drug Discov 2012; 11: 215-233.

10. Senovilla L, Vacchelli E, Galon J, Adjemian S, Eggermont A, Fridman WH et al. Trial watch: prognostic and predictive value of the immune infiltrate in cancer. Oncoimmunology 2012; 1: $1323-1343$.

11. Krysko DV, Garg AD, Kaczmarek A, Krysko O, Agostinis P, Vandenabeele P. Immunogenic cell death and DAMPs in cancer therapy. Nat Rev Cancer 2012; 12 860-875

12. Casares N, Pequignot MO, Tesniere A, Ghiringhelli F, Roux S, Chaput N et al. Caspasedependent immunogenicity of doxorubicin-induced tumor cell death. J Exp Med 2005; 202 1691-1701.

13. Martins I, Kepp O, Schlemmer F, Adjemian S, Tailler M, Shen S et al. Restoration of the immunogenicity of cisplatin-induced cancer cell death by endoplasmic reticulum stress. Oncogene 2011; 30: 1147-1158.

14. Obeid M, Tesniere A, Ghiringhelli F, Fimia GM, Apetoh L, Perfettini JL et al Calreticulin exposure dictates the immunogenicity of cancer cell death. Nat Med 2007; 13: $54-61$

15. Gardai SJ, McPhillips KA, Frasch SC, Janssen WJ, Starefeldt A, Murphy-Ullrich JE et al. Cell-surface calreticulin initiates clearance of viable or apoptotic cells through transactivation of LRP on the phagocyte. Cell 2005; 123: 321-334.

16. Panaretakis T, Kepp O, Brockmeier U, Tesniere A, Bjorklund AC, Chapman DC et al. Mechanisms of pre-apoptotic calreticulin exposure in immunogenic cell death. EMBO J 2009; 28: 578-590.

17. Garg AD, Krysko DV, Verfaillie T, Kaczmarek A, Ferreira GB, Marysael T et al. A novel pathway combining calreticulin exposure and ATP secretion in immunogenic cancer cell death. EMBO J 2012; 31: 1062-1079.

18. Menger L, Vacchelli E, Adjemian S, Martins I, Ma Y, Shen S et al. Cardiac glycosides exert anticancer effects by inducing immunogenic cell death. Sci Transl Med 2012; 4 143ra199.

19. Garg AD, Krysko DV, Vandenabeele P, Agostinis $P$. The emergence of phox-ER stress induced immunogenic apoptosis. Oncoimmunology 2012; 1: 786-788.

20. Raghavan M, Wijeyesakere SJ, Peters LR, Del Cid N. Calreticulin in the immune system: ins and outs. Trends Immunol 2013; 34: 13-21.

21. Nakamura M, Moriya M, Baba T, Michikawa Y, Yamanobe T, Arai K et al. An endoplasmic reticulum protein, calreticulin, is transported into the acrosome of rat sperm. Exp Cell Res 1993; 205: 101-110.

22. Tutuncu L, Stein P, Ord TS, Jorgez CJ, Williams CJ. Calreticulin on the mouse egg surface mediates transmembrane signaling linked to cell cycle resumption. Dev Biol 2004; 270: 246-260.

23. Nakamura M, Oshio S, Tamura A, Okinaga S, Arai K. Antisera to calreticulin inhibits sperm motility in mice. Biochem Biophys Res Commun 1992; 186: 984-990.
24. Park BJ, Lee DG, Yu JR, Jung SK, Choi K, Lee J et al. Calreticulin, a calcium-binding molecular chaperone, is required for stress response and fertility in Caenorhabditis elegans. Mol Biol Cell 2001; 12: 2835-2845.

25. Madeo F, Durchschlag M, Kepp O, Panaretakis T, Zitvogel L, Frohlich KU et al. Phylogenetic conservation of the preapoptotic calreticulin exposure pathway from yeast to mammals. Cell Cycle 2009; 8: 639-642.

26. Ferreira V, Valck C, Sanchez G, Gingras A, Tzima S, Molina MC et al. The classical activation pathway of the human complement system is specifically inhibited by calreticulin from Trypanosoma cruzi. J Immunol 2004; 172: 3042-3050.

27. Girard-Misguich F, Sachse M, Santi-Rocca J, Guillen N. The endoplasmic reticulum chaperone calreticulin is recruited to the uropod during capping of surface receptors in Entamoeba histolytica. Mol Biochem Parasitol 2008; 157: 236-240.

28. Vacchelli E, Galluzzi L, Fridman WH, Galon J, Sautes-Fridman C, Tartour E et al. Trial watch: chemotherapy with immunogenic cell death inducers. Oncoimmunology 2012; 1: $179-188$

29. Gardner BM, Walter P. Unfolded proteins are Ire1-activating ligands that directly induce the unfolded protein response. Science 2011; 333: 1891-1894.

30. Cole GM, Reed SI. Pheromone-induced phosphorylation of a G protein beta subunit in S. cerevisiae is associated with an adaptive response to mating pheromone. Cell 1991; 64: $703-716$.

31. Hildebrandt JD, Sekura RD, Codina J, lyengar R, Manclark CR, Birnbaumer L. Stimulation and inhibition of adenylyl cyclases mediated by distinct regulatory proteins. Nature 1983; 302: 706-709.

32. Kroemer G, Galluzzi L, Brenner C. Mitochondrial membrane permeabilization in cell death. Physiol Rev 2007; 87: 99-163.

33. Miyamoto S, Inoue H, Nakamura T, Yamada M, Sakamoto C, Urata Y et al. Coxsackievirus B3 is an oncolytic virus with immunostimulatory properties that is active against lung adenocarcinoma. Cancer Res 2012; 72: 2609-2621.

34. Paget C, Duret H, Ngiow SF, Kansara M, Thomas DM, Smyth MJ. Studying the role of the immune system on the antitumor activity of a Hedgehog inhibitor against murine osteosarcoma. Oncoimmunology 2012; 1: 1313-1322.

35. Zappasodi R, Pupa SM, Ghedini GC, Bongarzone I, Magni M, Cabras AD et al. Improved clinical outcome in indolent B-cell lymphoma patients vaccinated with autologous tumor cells experiencing immunogenic death. Cancer Res 2010; 70: 9062-9072.

36. Chao MP, Jaiswal S, Weissman-Tsukamoto R, Alizadeh AA, Gentles AJ, Volkmer J et al. Calreticulin is the dominant pro-phagocytic signal on multiple human cancers and is counterbalanced by CD47. Sci Transl Med 2010; 2: 63ra94.

37. Fucikova J, Kralikova P, Fialova A, Brtnicky T, Rob L, Bartunkova J et al. Human tumor cells killed by anthracyclines induce a tumor-specific immune response. Cancer Res 2011; 71: 4821-4833.

38. Haber JE. Mating-type genes and MAT switching in Saccharomyces cerevisiae. Genetics 2012; 191: 33-64.

39. Bauer MA, Carmona-Gutierrez D, Ruckenstuhl C, Reisenbichler A, Megalou EV, Eisenberg $\mathrm{T}$ et al. Spermidine promotes mating and fertilization efficiency in model organisms. Cell Cycle 2013; 12: 346-352.

40. Rajagopal S, Rajagopal K, Lefkowitz RJ. Teaching old receptors new tricks: biasing seventransmembrane receptors. Nat Rev Drug Discov 2010; 9: 373-386.

41. Mishra $P$, Banerjee D, Ben-Baruch A. Chemokines at the crossroads of tumor-fibroblast interactions that promote malignancy. J Leukoc Biol 2011; 89: 31-39.

42. Verbeke H, Struyf S, Laureys G, Van Damme J. The expression and role of CXC chemokines in colorectal cancer. Cytokine Growth Factor Rev 2011; 22: 345-358.

43. Pazolli E, Alspach E, Milczarek A, Prior J, Piwnica-Worms D, Stewart SA. Chromatin remodeling underlies the senescence-associated secretory phenotype of tumor stromal fibroblasts that supports cancer progression. Cancer Res 2012; 72 . 2251-2261.

44. Britschgi A, Andraos R, Brinkhaus $\mathrm{H}$, Klebba I, Romanet V, Muller U et al. JAK2/STAT5 inhibition circumvents resistance to $\mathrm{PI} 3 \mathrm{~K} / \mathrm{mTOR}$ blockade: a rationale for cotargeting these pathways in metastatic breast cancer. Cancer Cell 2012; 22: 796-811.

45. Piperi C, Samaras V, Levidou G, Kavantzas N, Boviatsis E, Petraki K et al. Prognostic significance of IL-8-STAT-3 pathway in astrocytomas: correlation with IL-6, VEGF and microvessel morphometry. Cytokine 2011; 55: 387-395.

46. Saintigny P, Massarelli E, Lin S, Ahn YH, Chen Y, Goswami S et al. CXCR2 expression in tumor cells is a poor prognostic factor and promotes invasion and metastasis in lung adenocarcinoma. Cancer Res 2013; 73: 571-582.

47. Hei TK, Zhou H, Chai Y, Ponnaiya B, Ivanov VN. Radiation induced non-targeted response: mechanism and potential clinical implications. Curr Mol Pharmacol 2011; 4: 96-105.

48. Frey B, Rubner Y, Wunderlich R, Weiss EM, Pockley AG, Fietkau R et al. Induction of abscopal anti-tumor immunity and immunogenic tumor cell death by ionizing irradiationimplications for cancer therapies. Curr Med Chem 2012; 19: 1751-1764.

49. Galluzzi L, Vacchelli E, Eggermont A, Fridman WH, Galon J, Sautes-Fridman C et al. Trial watch: experimental Toll-like receptor agonists for cancer therapy. Oncoimmunology 2012; $1:$ 699-716.

50. Vacchelli E, Galluzzi L, Eggermont A, Fridman WH, Galon J, Sautes-Fridman C et al. Trial watch: FDA-approved Toll-like receptor agonists for cancer therapy. Oncoimmunology 2012; 1: 894-907. 
51. Biot $\mathrm{C}$, Rentsch CA, Gsponer JR, Birkhauser FD, Jusforgues-Saklani $\mathrm{H}$, Lemaitre $\mathrm{F}$ et al. Preexisting BCG-specific T cells improve intravesical immunotherapy for bladder cancer. Sci Transl Med 2012; 4: 137ra172.

52. Thalmann GN, Sermier A, Rentsch C, Mohrle K, Cecchini MG, Studer UE. Urinary Interleukin- 8 and 18 predict the response of superficial bladder cancer to intravesical therapy with bacillus Calmette-Guerin. J Urol 2000; 164: 2129-2133.

53. DiPaola RS, Lattime EC. Bacillus Calmette-Guerin mechanism of action: the role of immunity, apoptosis, necrosis and autophagy. J Urol 2007; 178: 1840-1841.

54. Sheff MA, Thorn KS. Optimized cassettes for fluorescent protein tagging in Saccharomyces cerevisiae. Yeast 2004; 21: 661-670.

55. Galluzzi L, Morselli E, Vitale I, Kepp O, Senovilla L, Criollo A et al. miR-181a and miR-630 regulate cisplatin-induced cancer cell death. Cancer Res 2010; 70: 1793-1803.
56. Galluzzi L, Vitale I, Senovilla L, Olaussen KA, Pinna G, Eisenberg T et al. Prognostic impact of vitamin B6 metabolism in lung cancer. Cell Rep 2012; 2: 257-269.

57. Senovilla L, Vitale I, Martins I, Tailler M, Pailleret C, Michaud M et al. An immunosurveillance mechanism controls cancer cell ploidy. Science 2012; 337 1678-1684.

58. Galluzzi L, Aaronson SA, Abrams J, Alnemri ES, Andrews DW, Baehrecke EH et al. Guidelines for the use and interpretation of assays for monitoring cell death in higher eukaryotes. Cell Death Differ 2009; 16: 1093-1107.

59. Kepp O, Galluzzi L, Lipinski M, Yuan J, Kroemer G. Cell death assays for drug discovery. Nat Rev Drug Discov 2011; 10: 221-237.

60. Criollo A, Galluzzi L, Maiuri MC, Tasdemir E, Lavandero S, Kroemer G. Mitochondrial control of cell death induced by hyperosmotic stress. Apoptosis 2007; 12: 3-18.

Supplementary Information accompanies this paper on Cell Death and Differentiation website (http://www.nature.com/cdd) 